\title{
EL INCIDENTE DE NULIDAD DE ACTUACIONES
}

The Incident of Nullity of Actions

JORGE RODRÍGUEZ-ZAPATA PÉREZ

Universidad Nacional de Educación a Distancia

irzapata@telefonica.net

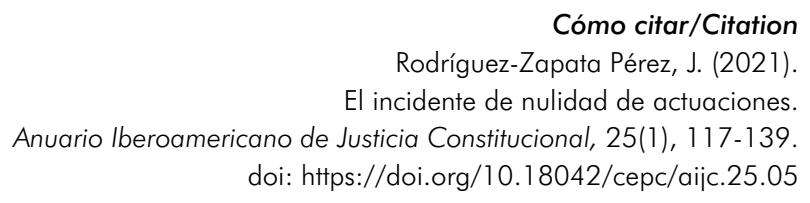

Resumen

El objetivo de este trabajo es realizar un estudio crítico del incidente de nulidad de actuaciones establecido en el art. 241 de la Ley Orgánica del Poder Judicial y en el art. 228 de la Ley de Enjuiciamiento Civil al objeto de plantear un balance de su efectividad.

\section{Palabras clave}

Incidente; nulidad.

\section{Abstract}

The aim of this article is to carry out a critical study of the incident of nullity of actions established in article 241 of the Organic Law of the Judiciary and in article 228 of the Law on Civil Procedure in order to take stock of its effectiveness.

Keywords

Incident; nullity. 
I. ANTECEDENTES DE LA NORMATIVA ACTUAL. II. REGULACIÓN ACTUAL DEL INCIDENTE DE NULIDAD DE ACTUACIONES: 1. Requisitos objetivos. 2. Órgano decisor. 3. Plazo. 4. Procedimiento. 5. Decisión y régimen de costas. 6. Recursos. III. EL INCIDENTE DE NULIDAD DE ACTUACIONES Y EL RECURSO DE AMPARO. IV. NATURALEZA JURÍDICA DEL INCIDENTE DE NULIDAD DE ACTUACIONES. V. BALANCE Y PERSPECTIVAS DE REFORMA. BIBLIOGRAFÍA.

\section{ANTECEDENTES DE LA NORMATIVA ACTUAL}

La Ley de Enjuiciamiento Civil de 1881 admitía un incidente de nulidad de actuaciones. Una doctrina jurisprudencial errática permitió que adquiriese una extensión desorbitada en todos los órdenes jurisdiccionales; la práctica forense lo hizo florecer - con vista, prueba y diversas instancias- convirtiéndolo en un arma procesal formidable que se esgrimía en forma abusiva y propiciaba confusión y dilaciones graves.

El legislador reaccionó y optó por la solución de abolirlo en la reforma de la Ley de Enjuiciamiento Civil operada por la Ley 34/1984, de 6 de agosto. Se reformaron los antiguos arts. 742 y $745.1^{\circ}$ LEC en el sentido drástico de disponer que «será inadmisible el incidente de nulidad de actuaciones» y que «los vicios que puedan producir tal efecto serán hechos valer a través de los correspondientes recursos» ${ }^{1}$. La innovación legal, discutida en vía de amparo, fue confirmada pronto por el Tribunal Constitucional ${ }^{2}$ y se consolidó. Desde entonces el incidente de nulidad de actuaciones desapareció totalmente de nuestra práctica procesal.

Sin embargo, la supresión hizo aflorar vicios procesales graves que no se remediaban en la jurisdicción ordinaria, porque no resultaba posible

Serra Domínguez (1985: 625) y Guasp (1950: 987).

2 Cfr. ATC 905/1985, de 13 de diciembre, FJ Único y Fallo y STC 113/1986 de 1 de octubre, FJ 2 y Fallo. La STC 15/1986, de 13 de enero, FJ 5 y Fallo declaró la improcedencia de tal incidente para declarar la nulidad de una sentencia tras la entrada en vigor de la Ley 34/1984. 
hacerlos valer a través de las vías de recurso, como exigía el art. 742 de la LEC reformada.

El legislador de 1984 había producido una laguna legal que no se llegó a colmar en el texto original de la Ley Orgánica 6/1985, de 1 de julio, del Poder judicial. La nueva LOPJ previó, en su art. 240, que el juez o tribunal pudiera, de oficio, antes de que hubiere recaído sentencia definitiva, declarar, previa audiencia de las partes, la nulidad de todas las actuaciones o de alguna en particular, pero la limitación del precepto a casos de nulidad producidos antes de que hubiera sentencia definitiva y a que el tribunal procediese de oficio dejó huérfanas de solución las hipótesis nada infrecuentes en las que era la propia resolución definitiva la que causaba la nulidad, señaladamente en los variados casos de incongruencia o en el de defectos en la constitución de la relación jurídica procesal. No existía ningún remedio para enmendar esos supuestos, por flagrantes que fueran, con la excepción de pedir la anulación de la resolución en vía de amparo ante el Tribunal Constitucional, lo que implicaba gastos para las partes y sobrecargaba de casos el recurso de amparo constitucional, que daba lugar además a una jurisprudencia repetitiva y de limitado interés. En algunas ocasiones las partes ejercitaban la posibilidad de poner de manifiesto al órgano judicial, para excitar sus potestades de revisión de oficio, que se habían dictado resoluciones jurisdiccionales que reputaban nulas, pero los tribunales, sin negarlo, se veían obligados a denegar la nulidad por imposibilidad de revisar una resolución definitiva fuera de la vía de recurso, aunque incluso se pusiera de manifiesto a los recurrentes la posibilidad de remediar el defecto por la vía del recurso de amparo ante el Tribunal Constitucional.

La situación se remedió en el año 1997 con la modificación de la LOPJ verificada por la Ley Orgánica 5/1997, de 4 de diciembre. Se añadió un apdo. 3 al viejo art. 240 LOPJ, que resucitó el viejo incidente de nulidad de actuaciones. A diferencia del de la LEC de 1881 se configuraba ahora en forma muy limitada y como un remedio excepcional para que las partes pudieran solicitar una nulidad de actuaciones para reparar los vicios de procedimiento que hubieran causado indefensión, así como los supuestos de incongruencia en el fallo siempre no hubiera sido posible denunciarlos antes de recaer sentencia o cuando no fuera posible denunciarlos por vía de recurso ${ }^{3}$. Se determinó que fuera competente para conocer de estos incidentes excepcionales el mismo

3 Al ser excepcional era un recurso manifiestamente improcedente cuando se formulaba al margen de los supuestos contemplados en el art. 241 LOPJ. Así lo declaró la STC 237/2006, de 7 de julio, FJ 3, para el principio de igualdad. Cfr. ATC 63/2008, de 25 de febrero. 
juzgado o tribunal que dictó la sentencia o resolución que hubiere adquirido firmeza. La reforma produjo resultados adecuados sin que se hiciera un uso desmedido de este incidente.

El incidente de nulidad también volvió a la nueva Ley de Enjuiciamiento Civil del año 2000 en su art. 228, aunque a reserva de lo dispuesto en la disposición final $17^{a}$ respecto a la modificación de la LOPJ, que se produjo en la Ley Orgánica 19/2003, de 23 de diciembre. La Ley de Enjuiciamiento Civil tiene carácter supletorio en todos los órdenes jurisdiccionales conforme a lo que dispone su art. 4, por lo que suele ser citada en ellos junto a la LOPJ.

La reforma de la LOPJ por la Ley Orgánica 19/2003, de 19 de diciembre, llevó también el incidente de nulidad al actual art. 241 de la LOPJ y lo decantó con mayor precisión, respetando los términos ya expuestos, que se han mantenido hasta la regulación actual.

Con la reforma del recurso de amparo por la Ley Orgánica 6/2007, de 24 de mayo, del Tribunal Constitucional pareció necesario que el incidente de nulidad de actuaciones adquiriese una dimensión más amplia; se modificó en tal sentido el art. 241 LOPJ, para intentar dar respuesta a la nueva situación creada por la reforma.

En efecto, la LOTC ha objetivado el recurso de amparo constitucional desde la reforma del año 2007, al exigir una nueva condición de admisibilidad del mismo: su especial trascendencia constitucional ${ }^{4}$. Con ello el amparo ha sufrido una reducción drástica que ha aliviado al Tribunal Constitucional de una carga que consumía la mayor parte del tiempo de dedicación de sus magistrados y que no podía soportar. En la actualidad el solicitante de amparo está obligado a justificar formalmente la especial trascendencia constitucional de su recurso, lo que es un requisito procesal que la doctrina del Tribunal Constitucional ha considerado objetivo e insubsanable. El recurso de amparo constitucional se ha convertido en un recurso extraordinario que opera únicamente por el motivo de la especial trascendencia constitucional del art. 50.1 b) de la LOTC. La configuración del recurso de amparo como un recurso limitado y reservado para los supuestos de trascendencia constitucional ha producido una inadmisión en masa de los recursos de amparo. En

4 Este requisito se configura como una carga procesal del recurrente y como un instrumento de colaboración del mismo con la justicia constitucional que se ha de cumplir en el escrito de demanda de amparo (STC 69/2011, de 16 de mayo, FJ 3). El TC declara que su ausencia es insubsanable porque la interposición del recurso de amparo está sujeta a plazos de caducidad preclusivos, que no pueden ser reabiertos para dar cumplimiento a un requisito que afecta directamente a la determinación misma de la pretensión deducida en el recurso de amparo (Rodríguez-Zapata, 2018: 332). 
esa situación el legislador intentó configurar en forma plausible el incidente de nulidad de actuaciones como un remedio alternativo a acudir al Tribunal Constitucional en todos aquellos casos en los que hubiera existido una lesión de un derecho fundamental, sin que el supuesto revistiese trascendencia constitucional que justificase la admisión de un recurso de amparo constitucional para remediarla. Se modificó así el art. 241 LOPJ por la disposición final $1^{a}$ de la Ley Orgánica 6/2007, de 24 de mayo, de reforma del Tribunal Constitucional con una intención que la propia Exposición de motivos de la Ley Orgánica 6/2007 expresó en los siguientes términos:

La protección y garantía de los derechos fundamentales no es una tarea única del Tribunal Constitucional, sino que los tribunales ordinarios desempeñan un papel esencial y crucial en ella. Por ello, y con la intención de aumentar las facultades de la jurisdicción ordinaria para la tutela de los derechos fundamentales, se modifica el incidente de nulidad de actuaciones del artículo 241.1 de la Ley Orgánica 6/1985, de 1 de julio. De este modo se introduce una configuración del incidente de nulidad de actuaciones mucho más amplia, porque se permite su solicitud con base en cualquier vulneración de alguno de los derechos fundamentales referidos en el artículo 53.2 de la Constitución en lugar de la alegación de indefensión o incongruencia prevista hasta el momento. Esta ampliación del incidente de nulidad de actuaciones previo al amparo busca otorgar a los tribunales ordinarios el papel de primeros garantes de los derechos fundamentales en nuestro ordenamiento jurídico.

Además de esta «ampliación» hay que destacar, por último, la modificación del recurso de casación contencioso-administrativo por la disposición final $3^{a}$ de la Ley Orgánica 7/2015, de 21 de julio. Esta reforma ha creado el recurso de casación por interés casacional en el que se ha eliminado en forma sustancial la doble instancia en el orden contencioso-administrativo y se ha objetivado también el recurso de casación, copiando en forma muy apresurada la reforma del recurso de amparo del año $2007^{5}$. La inadmisión en masa, esta vez de recursos de casación contencioso-administrativos — según el potente "filtro de admisión» creado por la reforma de 2015ha llevado a la jurisprudencia ordinaria a tratar de paliar la grave carencia de una doble instancia en lo contencioso-administrativo dando nuevas y complejas dimensiones al incidente de nulidad de actuaciones, que expondré más adelante.

5 Rodríguez-Zapata (2019: 305). 


\section{REGULACIÓN ACTUAL DEL INCIDENTE DE NULIDAD DE ACTUACIONES}

El incidente de nulidad de actuaciones es hoy un medio de impugnación de carácter excepcional, por el que se reconoce a las partes el derecho a instar la declaración de nulidad de aquellas actuaciones procesales posteriores a la resolución definitiva del proceso que no puedan eliminarse con otros remedios.

El art. 241.1 LOPJ dispone que no se admitirán con carácter general incidentes de nulidad de actuaciones pero que, sin embargo, excepcionalmente, quienes sean parte legítima o hubieran debido serlo podrán pedir por escrito que se declare la nulidad de actuaciones fundada en cualquier vulneración de un derecho fundamental de los referidos en el art. 53.2 de la Constitución, siempre que no haya podido denunciarse antes de recaer resolución que ponga fin al proceso y siempre que dicha resolución no sea susceptible de recurso ordinario ni extraordinario.

Será competente para conocer de este incidente el mismo juzgado o tribunal que dictó la resolución que hubiere adquirido firmeza.

El plazo para pedir la nulidad es de veinte días, desde la notificación de la resolución o, en todo caso, desde que se tuvo conocimiento del defecto causante de indefensión, sin que, en este último caso, pueda solicitarse la nulidad de actuaciones después de transcurridos cinco años desde la notificación de la resolución.

El juzgado o tribunal inadmitirá a trámite, mediante una providencia motivada en forma sucinta, cualquier incidente en el que se pretenda suscitar otras cuestiones.

Contra la resolución por la que se inadmita a trámite el incidente no cabrá recurso alguno.

Cuando se admite a trámite el escrito en que se pida la nulidad no queda en suspenso la ejecución y eficacia de la sentencia o resolución, salvo que se acuerde de forma expresa la suspensión para evitar que el incidente pudiera perder su finalidad.

Se dará traslado del escrito de petición de nulidad, junto con copia de los documentos que se acompañasen, en su caso, para acreditar el vicio o defecto en que la petición se funde, a las demás partes, para que en el plazo común de cinco días formulen sus alegaciones por escrito, a las que acompañarán los documentos que estimen pertinentes.

Si se estimara la nulidad, se repondrán las actuaciones al estado inmediatamente anterior al defecto que la haya originado y se seguirá el procedimiento legalmente establecido. Si se desestimara la solicitud de nulidad, se condenará, por medio de auto, al solicitante en todas las costas del incidente. 
En caso de que el juzgado o tribunal entienda que se promovió con temeridad, impondrá, además, una multa de 90 a 600 euros.

Contra la resolución que resuelva el incidente no cabrá recurso alguno.

\section{REQUISITOS OBJETIVOS}

Tanto el art. 241.1 LOPJ como el 228.1 LEC exigen que la resolución que se impugna mediante el incidente de nulidad no sea susceptible de recurso ordinario ni extraordinario.

\section{2. ÓRGANO DECISOR}

Conforme al art. 241.1. $2^{\circ}$ LOPJ y al 228.2 LEC, será competente para conocer de este incidente el mismo juzgado o tribunal que dictó la resolución que hubiere adquirido firmeza.

El Tribunal Supremo se ha pronunciado sobre esta circunstancia y ha declarado que la circunstancia de que conozca del incidente de nulidad el mismo órgano que dictó la sentencia no supone riesgo para la exigencia constitucional de que el juzgador posea imparcialidad objetiva. Así lo ha señalado también el Tribunal Constitucional en la STC 108/2013. Resolvió una reclamación en la que se alegaba que la petición de nulidad de actuaciones debió ser resuelta por magistrados de la Sala distintos de los que dictaron el auto cuya nulidad se pretendía, por entenderse que estos estarían condicionados por su conocimiento anterior del caso. El Tribunal Constitucional señala que esa pretensión es contraria a la regulación positiva del incidente de nulidad de actuaciones y descarta que atente a las garantías constitucionales del proceso que el mismo órgano que dictó la resolución pueda conocer de la petición de su nulidad. No hay exigencias de constitucionalidad, dice, que lleven a excluir la competencia del órgano que dictó la resolución que se pretende anular para decidir sobre su anulación. La jurisprudencia del Tribunal Supremo sigue esta doctrina y ha añadido que una solución distinta presentaría además graves problemas de viabilidad en los casos de órganos judiciales unipersonales o colegiados con dotación insuficiente para exigir un cambio de composición en el órgano que decide sobre la nulidad ${ }^{6}$.

6 Conf. Auto 3/2015 de la Sala especial del art. 61 de la LOPJ, de 17 de junio de 2015, ponente Jorge Rodríguez-Zapata (rec. 3/2015), con cita de las sentencias del TEDH de 4 y de 20 de enero de 2015, asuntos Warszicka v. Poland $\$ 4$ y Arribas Antón contra España. 


\section{PLAZO}

El plazo para pedir la nulidad será de 20 días, desde la notificación de la resolución o, en todo caso, desde que se tuvo conocimiento del defecto causante de indefensión, sin que, en este último caso, pueda solicitarse la nulidad de actuaciones

Los plazos de interposición se interrumpen si se formula una petición de aclaración, rectificación, subsanación o complemento de la resolución definitiva firme en relación con la que se formula el incidente (art. 267.9 LOPJ).

\section{PROCEDIMIENTO}

El juzgado o tribunal inadmitirá a trámite, mediante providencia sucintamente motivada, cualquier incidente en el que se pretenda suscitar otras cuestiones que las señaladas anteriormente, ceñidas a la posible lesión de un derecho fundamental que sea atribuible ex novo a la sentencia o resolución que cierra el proceso, sin que quepa en dicho incidente el replanteamiento integral del fondo del asunto para que el tribunal sentenciador reconsidere su decisión. La jurisprudencia ordinaria es muy tajante en esta exigencia, que lleva a la inadmisión de una gran parte de los incidentes interpuestos.

Contra la providencia de inadmisión por la que se inadmita a trámite el incidente no cabrá recurso alguno.

En caso de que sea admitido a trámite el escrito en que se pida la nulidad fundada en los vicios a que se refiere el art. 241.1 LOPJ no quedará en suspenso la ejecución y eficacia de la sentencia o resolución irrecurribles, salvo que se acuerde de forma expresa la suspensión para evitar que el incidente pudiera perder su finalidad, y se dará traslado de dicho escrito, junto con copia de los documentos que se acompañasen, en su caso, para acreditar el vicio o defecto en que la petición se funde, a las demás partes, que en el plazo común de cinco días podrán formular por escrito sus alegaciones, a las que acompañarán los documentos que se estimen pertinentes.

\section{DECISIÓN Y RÉGIMEN DE COSTAS}

Se produce en forma de auto si el incidente fue admitido a trámite y por providencia en el caso contrario.

Si se estimara la nulidad, se repondrán las actuaciones al estado inmediatamente anterior al defecto que la haya originado y se seguirá el procedimiento legalmente establecido. 
Si se desestimara la solicitud de nulidad, se condenará, por medio de auto, al solicitante en todas las costas del incidente. La inadmisión por providencia no lleva aparejada condena en costas.

Cuando el juzgado o tribunal entienda que el incidente se promovió con temeridad impondrá, además, al promotor una multa de 90 a 600 euros.

\section{RECURSOS}

Contra la resolución que resuelva por auto el incidente admitido a trámite no cabrá recurso alguno (art. 241.2 «in fine» LOPJ).

Tampoco cabrá recurso contra su inadmisión por providencia (art. 241.1 in fine LOPJ).

\section{EL INCIDENTE DE NULIDAD DE ACTUACIONES Y EL RECURSO DE AMPARO}

Como se ha visto, el incidente de nulidad de actuaciones ya no se limita en el art. 241 de la LOPJ a los casos de «defectos de forma que hayan causado indefensión o en los supuestos de incongruencia del fallo", sino que se extiende a «cualquier vulneración de un derecho fundamental de los referidos en el artículo 53.2 de la Constitución». Es obvio que, de tal forma sigue cubriendo también los anteriores defectos de forma, en la medida en que - siempre con una interpretación no restrictiva- se considere que afectan al derecho a una tutela judicial efectiva del art. 24 de la Norma Fundamental ${ }^{7}$.

En un primer momento la jurisprudencia del Tribunal Constitucional se orientó en el sentido de obligar a los tribunales ordinarios a considerar el incidente como un recurso con sustantividad propia; declaró que no puede considerarse como un mero trámite formal previo al amparo constitucional, sino como un verdadero instrumento procesal que, en la vía de la jurisdicción ordinaria, está llamado a remediar aquellas lesiones de derechos fundamentales que no hayan "podido denunciarse antes de recaer resolución que ponga fin al proceso y siempre que dicha resolución no sea susceptible de recurso ordinario ni extraordinario" (art. 241.1 LOPJ). En definitiva, se subrayaba que el incidente de nulidad de actuaciones debía servir tras la reforma del año 2007 para reparar las lesiones de cualquier derecho fundamental que no pudiera serlo a través de los recursos ordinarios o extraordinarios previstos por la ley, porque una protección deficiente de los derechos denunciados por

7 Rodríguez-Zapata (2013: 241). 
parte del órgano judicial dejaría al recurrente sin ningún tipo de protección en aquellos casos en los que las vulneraciones en las que supuestamente incurriera la resolución impugnada a través del incidente de nulidad de actuaciones carecieran de trascendencia constitucional a efectos de la admisión del nuevo recurso de amparo.

Las nuevas exigencias para evitar una protección deficiente se planteaban en dos frentes:

a) La anulación de las resoluciones jurisdiccionales que inadmitiesen de plano los incidentes de nulidad, empleando una interpretación restrictiva de sus requisitos o sin la debida motivación.

b) La procedencia de estos incidentes frente a las lesiones de derechos fundamentales tanto sustantivos como procedimentales

a) En un primer momento la jurisprudencia constitucional estableció que, salvo que se dieran causas de inadmisión de plano, los órganos judiciales estaban obligados a realizar una interpretación no restrictiva de los motivos de inadmisión, a tramitar el incidente de nulidad sin que fuera admisible una inadmisión a limine por providencia y a motivar, en cualquier caso, suficientemente la decisión que se adoptase. En ese sentido se pronunció la Sentencia de la Sala Segunda del TC 153/2012, de 16 de julio (FJ 3 y Fallo).

Sin embargo, dicha doctrina fue rectificada muy pronto, por lo que el incidente de nulidad perdió la posibilidad de ser una alternativa a los recursos de amparo en los que hubiera lesión y no existiera trascendencia constitucional que había previsto el legislador del año 2007. Otra sentencia, esta vez de la Sala Primera del Tribunal Constitucional, sirvió para negar sustantividad al incidente, que pasó a denominarse simple «remedio procesal» que no puede suponer una vulneración autónoma de derechos, admitiéndose que el mismo se puede rechazar a limine con una simple providencia motivada ${ }^{8}$.

8 La contradicción de doctrina se aprecia ya en la STC 180/2012, de 15 de octubre, en cuyo FJ 4 se intenta justificar expresamente el cambio de criterio frente a lo que se afirma en la STC 153/2012. La rectificación es patente, sin embargo, en la STC 2/2013 de 14 de enero, cuyo FJ 5 entiende ahora que es suficiente una simple providencia motivada para inadmitir un incidente de nulidad de actuaciones. Las SSTC 11/2013, de 28 de enero (FJ 2, penúltimo párrafo) y 56/2013, de 11 de marzo, contradicen ya en forma clara la doctrina fijada en la STC 153/2012. La última afirma, frente a una queja de falta de motivación de una providencia de inadmisión dictada por la Sala Primera del Tribunal Supremo que «no toda providencia de inadmisión de un incidente de nulidad, por el mero hecho de serlo, merece reproche desde la óptica que se predica, debiendo atenderse no solo al texto de la resolución judicial sino al 
Esta orientación se ha mantenido hasta la actualidad.

b) El mismo cambio de orientación se produjo respecto de la ampliación del incidente a todos los derechos fundamentales reconocidos en el art. 53.2 $\mathrm{CE}$ que pronto pasó de considerarse que abarcaba derechos fundamentales sustantivos y procesales a reducirse de nuevo a las lesiones de los derechos fundamentales ocasionadas por la última resolución impugnada, lo que en apariencia parece reducir la queja a los supuestos de vulneración de la tutela judicial efectiva del art. $24 \mathrm{CE}$.

El ATC 200/2010, de 21 de diciembre, fue paradigmático de la primera orientación, al inadmitir un recurso de amparo por falta de agotamiento de la vía judicial previa por falta de interposición del incidente de nulidad de actuaciones respecto de la vulneración de derechos fundamentales inequívocamente sustantivos ${ }^{9}$. El auto recuerda la necesidad de salvaguardar la naturaleza

contenido del escrito por el que dicho incidente se solicita» (FJ 4). La rectificación fue advertida, de inmediato, por los órganos de la jurisdicción ordinaria que, desde entonces, y empezando por la práctica del Tribunal Supremo, empezaron a inadmitir por providencia motivada, en forma sucinta, la mayor parte de los incidentes de nulidad de actuaciones. La STC 135/2017, de 27 de noviembre, y 9/2014, de 27 de enero, da cuenta de la doctrina actual tras este viaje jurisprudencial que queda como algo inadvertido para la propia jurisprudencia constitucional. Se concede en la STC 135/2017 el amparo frente a una providencia de inadmisión claramente apodíctica declarando que «el incidente de nulidad de actuaciones no constituye un recurso en sentido estricto [...] es un cauce procesal que [...] debe ser enjuiciado desde el canon propio del derecho de acceso al recurso legalmente establecido. [...] Por ello el Tribunal se ha de limitar a comprobar si la resolución de inadmisión está motivada y si ha incurrido o no en error material patente, en arbitrariedad o en manifiesta irrazonabilidad lógica, evitando toda ponderación acerca de su corrección jurídica» (FJ 4).

9 El auto inadmite un recurso de amparo formulado contra una sentencia de la Sala Primera del Tribunal Supremo por supuesta vulneración del derecho a la libertad de expresión (art. 20.1 CE) en conflicto con el derecho al honor del art. 18.1 CE, que dicha sentencia había considerado prevalente. El FJ 2 del Auto declara que «mal podría encajar el propósito de potenciación o reforzamiento del carácter subsidiario del amparo [...] a través de una mayor exigencia del incidente de nulidad de actuaciones, si respecto de los conflictos suscitados en el ámbito de conductas imputables a los particulares, en relación con derechos fundamentales sustantivos, se entendiera que la vulneración a la que se refiere el art. 44.1 LOTC lo es también la producida por éstos, y que la "denuncia" de la lesión se consuma ya con la presentación por el afectado de la demanda de primera instancia. De interpretarse así nunca se cumpliría con el presupuesto legal para la procedencia del incidente, esto es, que la lesión "no haya podido denunciarse antes de recaer resolución que ponga fin al proceso", con lo que devendría virtualmente inaplicable y, por ese camino, el incidente de nulidad de 
subsidiaria del recurso de amparo a fin de evitar que el Tribunal Constitucional se pronuncie sobre eventuales vulneraciones de derechos fundamentales o libertades públicas cuando ese pronunciamiento pueda aún hacerse por los órganos de la jurisdicción ordinaria a través de las vías procesales establecidas y entiende que en el caso de una sentencia dictada en casación por la Sala Primera del Tribunal Supremo era exigible a la parte recurrente promover el incidente de nulidad de actuaciones del art. 241 de la Ley Orgánica del Poder Judicial (LOPJ) antes de acudir en amparo al Tribunal Constitucional, a pesar de que los hechos del caso venían siendo debatidos ya desde la primera instancia y concluyó que era necesario para un correcto agotamiento de la vía judicial previa que se interpusiese el incidente de nulidad para denunciar cualquier derecho fundamental que se considerase vulnerado, tanto si se trataba de derechos fundamentales sustantivos como procesales siempre que no hubiera podido denunciarse antes de que recayera la resolución que ponía fin al proceso y que dicha resolución no fuera susceptible de recurso.

La STC 176/2013, de 21 de octubre, supuso un cambio de criterio radical (overrule) frente a la resolución anterior. El Ministerio Fiscal había opuesto en este caso como óbice de procedibilidad, con apoyo expreso en la doctrina sentada en el ATC 200/2010, que no procedía admitir a trámite una demanda de amparo por la que un ministro del Gobierno de la época reclamaba su derecho a la intimidad y la propia imagen también frente a una sentencia de la Sala Primera del Tribunal Supremo. Esta, tras casar y revocar dos sentencias anteriores, había entendido que debía primar la libertad de información de unos paparazzi que grabaron subrepticiamente imágenes del personaje público en unas vacaciones en un hotel de Lanzarote, para difundirlas como entretenimiento en un programa de televisión de ámbito nacional sobre sus derechos sustantivos a la intimidad y a la propia imagen del art. 18.1 CE.

Sostenía el fiscal que el demandante de amparo no habría agotado la vía judicial previa conforme a la jurisprudencia entonces vigente, como exige el art. 44.1 a) de la LOTC, al no haber interpuesto el incidente de nulidad de actuaciones previsto en el art. 241.1 de la LOPJ, en la redacción dada al mismo por la Ley Orgánica 6/2007, de 24 de mayo, el cual resultaba evidente conforme a la doctrina del ATC 200/2010.

El Tribunal rechaza ahora esta oposición sin reconocer que estaba cambiando su jurisprudencia anterior. Razona que no debe perderse de vista que el incidente de nulidad de actuaciones solo es exigible para consi-

actuaciones quedaría reducido a la reparación de los derechos fundamentales del art. $24 \mathrm{CE}$. Una restricción desde luego no expresada por el legislador e incompatible con el objetivo asignado a la reforma legal de 2007». 
derar correctamente agotada la vía judicial en la medida en que se pueda lograr con su utilización la reparación de los derechos fundamentales que se pretenden vulnerados. El objeto central de la controversia en el caso había consistido en determinar si se habían vulnerado los derechos del recurrente a la propia imagen y a la intimidad o si, por el contrario, la conducta del demandando se encontraba amparada por el ejercicio del derecho a la información, obteniéndose una respuesta judicial no uniforme en las sentencias de instancia y apelación, por una parte, y casación, por la otra.

Sostiene la STC 176/2013 que, de haber planteado el incidente de nulidad de actuaciones, los recurrentes habrían denunciado la conculcación, por parte de la sentencia dictada al resolver el recurso de casación, de los mismos derechos fundamentales que tanto la sentencia dictada en la instancia como la recaída al resolver el recurso de apelación conocieron en el proceso civil, supuesto que, por cierto, también podía predicarse del caso resuelto por el ATC 200/2010. Ahora, no obstante, el tribunal pondera que ello habría supuesto que la interposición del incidente de nulidad habría tenido por objeto el replanteamiento integral de la estimación del recurso interpuesto por aquellos, es decir su desestimación, con la consiguiente modificación radical del fallo y de la fundamentación jurídica utilizada para reconocer la prevalencia del derecho a difundir información en el caso concreto. Y concluye que, en tales condiciones, no puede reprocharse al demandante que no plantease ante la propia Sala Primera del Tribunal Supremo - la misma del ATC 200/2010 - incidente de nulidad de actuaciones, con la pretensión de que este reconsiderase el fondo de su resolución con argumentos semejantes a los ya empleados en la vía judicial. El incidente de nulidad resultaba materialmente inútil porque comportaba "pedir al órgano judicial que se retractase sobre lo que ya había resuelto en su sentencia previa».

La STC 112/2019 establece una nueva rectificación por la vía de un criterio más matizado establecido por la vía de distinguir (distinguish) en la doctrina constitucional los supuestos en los que la inadmisión de una pretensión de nulidad por vulneración de derechos fundamentales se debe a un recurso que sea inadmitido por razones procesales — supuesto normal hoy de los recursos de casación por interés casacional objetivo- que no son atribuibles a falta de diligencia de la parte recurrente y dejan imprejuzgada la cuestión constitucional planteada. La STC 112/2019 llega a la conclusión de que no es preciso interponer en esos casos un incidente de nulidad de actuaciones ante el tribunal sentenciador.

Resulta de esta jurisprudencia constitucional que la naturaleza subsidiaria del amparo no debe llevar a una cadena ilimitada de recursos. El requisito del agotamiento de los recursos a efectos del art. 44.1 a) LOTC ha de interpretarse, y así lo hace el Tribunal Constitucional, en forma flexible y finalista. Ese 
requisito no obliga a utilizar todos los medios de impugnación posibles, sino solo aquellos que se manifiesten de forma clara como ejercitables sin necesidad de efectuar unas interpretaciones mayores de las exigibles racionalmente.

Este resultado de la jurisprudencia constitucional ha vuelto a limitar la potencialidad del incidente de nulidad de actuaciones. Reducirlo a la última resolución y limitarlo a cuestiones nuevas no planteadas anteriormente en el proceso llevó a que la inadmisión en masa de recursos de amparo motivada por la reforma del año 2007 no pudiese ser colmada por el incidente que nos ocupa. Un sector de la doctrina ha pedido, pura y simplemente, que se suprima el incidente del art. 241 LOPJ o que se limite a infracciones del art. $24 \mathrm{CE}$, con exclusión de la infracción de derechos sustantivos. Esta es la situación actual que resulta claramente insatisfactoria para nuestro Estado social y democrático de derecho.

\section{NATURALEZA JURÍDICA DEL INCIDENTE DE NULIDAD DE ACTUACIONES}

El art. 241 LOPJ se encuentra en el campo de la legalidad ordinaria y ha sido la jurisprudencia ordinaria la que ha definido el incidente de nulidad de actuaciones y ha precisado su naturaleza jurídica, haciendo uso, como no podía ser de otra forma, de las declaraciones que se extraen de la doctrina del Tribunal Constitucional que se acaba de exponer.

La jurisprudencia del Tribunal Supremo subraya ante todo que la nulidad de actuaciones tiene naturaleza incidental. Recuerda que, en el supuesto hipotético de que el incidente fuera estimado, condicionaría el efecto de cosa juzgada, en la medida en que esa estimación comportaría reponer las actuaciones al estado inmediatamente anterior al defecto que lo haya originado. Por ello no es un recurso autónomo sino un auténtico incidente, que forma parte del proceso al que sigue cronológicamente y que se encuentra sometido a su mismo régimen de plazos $^{10}$.

10 Auto del Tribunal Supremo 10233/2017, de 24 de octubre (ponente, J. Rodríguez-Zapata) (ECLI:ES:TS:2017:10233A). No faltan resoluciones jurisprudenciales del Tribunal Supremo (Salas Segunda y Tercera) que ponen énfasis en una sustantividad del incidente como si fuera un recurso excepcional, siguiendo lo que se afirma en algunas resoluciones del Tribunal Constitucional a las que hemos pasado revista. Estas decisiones no extraen, sin embargo, ninguna consecuencia jurídica de la afirmación de la sustantividad del incidente. 
La Sala Especial del art. 61 de la LOPJ actúa como una especie Sala resumen de todo el Tribunal Supremo, que sintetiza la jurisprudencia de sus distintas Salas. El auto de esa Sala Especial de 17 de junio de $2015^{11}$ insiste en que el incidente es la forma de satisfacción última de los derechos fundamentales ante la jurisdicción ordinaria y que se constituye como el cauce natural para su remedio. Su materia exclusiva y excluyente ha de ser la vulneración de un derecho fundamental, no cualquier infracción legal, con las excepciones que enumera la propia Sala. No entra la Sala en la insuficiencia de la regulación legal vigente para lograr ese objetivo ni efectúa — no sería pertinente que lo hiciese- consideraciones de lege ferenda.

Se insiste por la jurisprudencia en que tal incidente, en la regulación emanada de la reforma del año 2007, que ya hemos visto, solo es idóneo para acoger la denuncia de violaciones de derechos fundamentales en congruencia con la filosofía que inspiró la modificación, que es la de (poner en manos de la jurisdicción ordinaria una herramienta para solventar —en forma acelerada y con inmediación - eventuales vulneraciones de derechos fundamentales que no hubiesen podido denunciarse con anterioridad antes de acudir al amparo constitucional. Se precisa que la regulación existente no ofrece riesgos para la imparcialidad objetiva, que exige la jurisprudencia constitucional, en sintonía con la del Tribunal Europeo de Derechos Humanos, por el hecho de que conozca del incidente el mismo órgano que dictó la sentencia ${ }^{12}$. Por ello el incidente se resuelve por el mismo Tribunal sentenciador, que es su juez natural, y su objeto se ciñe a la posible lesión de un derecho fundamental atribuible ex novo a la sentencia o resolución que cierra el proceso. Ha surgido como un medio de impugnación excepcional que permite obtener en la vía procesal ordinaria la declaración de nulidad de una sentencia o de las actuaciones procesales posteriores siempre que no haya sido posible eliminarlas con otros remedios procesales ${ }^{13}$.

11 Auto 5757/2015, de 17 de junio de 2015 [(ECLI:ES:TS:2015:5757) (ponente, J. Rodríguez-Zapata, (error judicial A61/11/2011) con cita de otro de la misma Sala Especial 9 de marzo de 2012].

12 Conf., ampliamente, Auto del Tribunal Supremo 1788/2020 de 16 de enero de 2020, ponente, J. Rodríguez-Zapata (ECLI:ES:TS: 2020:1788A).

13 El incidente de nulidad de actuaciones no es un recurso más, sino un remedio al que se puede acudir «excepcionalmente» para reparar la vulneración de un derecho fundamental de los referidos en el art. 53.2 CE, «siempre que no haya podido denunciarse antes de recaer resolución que ponga fin al proceso y siempre que dicha resolución no sea susceptible de recurso ordinario ni extraordinario». Es manifiestamente improcedente cuando en el incidente se denuncia una irregularidad que no se imputa originariamente a la sentencia impugnada sino a una resolución anterior porque no se trataría 
En un Auto de 29 de noviembre de 2018 la Sala Especial del art. 61 resume la doctrina recaída en las distintas salas, declarando que el incidente excepcional de nulidad de actuaciones ha quedado configurado en la modificación operada por la disposición final $1 .^{a} \mathrm{LO}$ 6/2007, 24 de mayo, como la forma de satisfacción última de los derechos fundamentales ante la jurisdicción ordinaria, constituyéndose en el cauce natural para su remedio.

También recuerda la jurisprudencia del Tribunal Supremo que desde la STC 216/2013, 19 de diciembre, FJ 2, la doctrina del Tribunal Constitucional matiza su necesidad en la forma que ya hemos expresado y considera innecesario promover el incidente excepcional de nulidad de actuaciones para entender agotadas todas las instancias judiciales antes de acudir al amparo cuando el propio objeto del proceso en el que se plantea el incidente consiste en la posible vulneración de derechos fundamentales, de forma que la posible lesión del derecho fundamental no sea atribuible ex novo a la sentencia que cierra la vía judicial previa al amparo. El incidente procede cuando la lesión del derecho fundamental sea una cuestión nueva, no debatida antes. Considera que fuera de este supuesto ha de entenderse que antes de acudir al amparo constitucional debe promoverse el incidente excepcional de nulidad de actuaciones para intentar solventar ante la jurisdicción ordinaria eventuales vulneraciones de derechos fundamentales que no hubiesen podido denunciarse con anterioridad.

La relevancia de este medio de impugnación se manifiesta especialmente como mecanismo de agotamiento de la vía judicial previa en relación con la naturaleza subsidiaria del recurso de amparo (STC 32/2010, de 8 de julio, FJ 2). No se cierra la vía a que ello impida que sea también idóneo en otras perspectivas para restablecer eventuales vulneraciones de derechos fundamentales (STC 43/2010, de 26 de julio, FFJ 2 y 5), lo que lo convierte en remedio adecuado antes de acudir a otras vías de reparación excepcional de derechos.

Basándose en dicha doctrina, la Sala del art. 61 LOPJ ha dado un paso más y ha configurado el incidente de nulidad de actuaciones como un remedio de exigencia previa inexcusable antes de obtener la reparación excepcional del derecho de un recurrente que supone la declaración de error judicial. A este respecto, y dado que el incidente de nulidad se configura como una corrección interna dentro del propio ámbito judicial de las infracciones de

en tal caso de una supuesta lesión de un derecho fundamental «que no haya podido denunciarse antes de recaer resolución que ponga fin al proceso», como exige el art. 241.1 LOPJ [(ATC 42/2010, de 12 de abril, FJ 2 y Fallo)]. Conf., por todas, STC 216/213, de 19 de diciembre (FJ 2). Cfr. Auto 3/2015 de la Sala Especial del art. 61 de la LOPJ, de 17 de junio de 2015 (rec. 3/2015), ponente, Jorge Rodríguez-Zapata. 
los derechos fundamentales, la Sala Especial del art. 61 ha entendido que es una razón de lógica jurídica la que empuja a incluir el incidente de nulidad de actuaciones en el ámbito del art. 293.1.f) LOPJ. Se ha convertido así en la actualidad como una forma de agotar dentro de la propia esfera jurisdiccional las posibilidades de subsanación y corrección del error judicial, apurando las posibilidades de dar a la parte una respuesta judicial a su pretensión, dado que la eventual sentencia estimatoria de una demanda de error judicial no colmaría ese derecho, pues solo daría, a lo sumo, derecho a una indemnización por el error sufrido ${ }^{14}$.

Un paso ulterior se ha producido, aun, con la reforma del recurso de casación producida en la Ley Orgánica 7/2015, de 21 de julio, a la que ya he hecho referencia. El incidente de nulidad también se ha configurado en la nueva situación procesal creada por esta reforma como un cauce nuevo e idóneo para resolver los vicios de procedimiento (errores in procedendo) cometidos en las sentencias susceptibles del nuevo recurso de casación por interés casacional objetivo ante la justicia ordinaria. Todo ello porque el recurso de casación contencioso-administrativo también se ha objetivado tras la reforma de la Ley reguladora de la jurisdicción contencioso-administrativa por la Ley Orgánica 7/2015 de 21 de julio ${ }^{15}$.

Resulta que, tras esa reforma operada en la LJCA por la Ley 7/2015, los "errores in procedendo» también son denunciables en la nueva casación por interés objetivo para unificar jurisprudencia, como lo eran obviamente con anterioridad. Pero estas infracciones formales han sido las más afectadas por la naturaleza objetiva del nuevo recurso de casación por interés objetivo ya que las infracciones de normas procesales (ad exemplum, pertinencia y relevancia de la prueba, valoración de la prueba, congruencia, motivación o litispendencia) han quedado en forma casi necesaria fuera del nuevo recurso por el hecho de que existe ya una jurisprudencia muy repetida, pacífica $-y$ tanto constitucional como ordinaria—, sobre la mayor parte de dichas infracciones procedimentales, por lo que lo más lógico sería, en concreto, que, ante una sentencia incongruente se inadmitiese el nuevo recurso de casación por interés casacional objetivo por existir sobrada jurisprudencia sobre todas y cada una de las formas de incongruencia. El supuesto es paralelo y muy similar al de la existencia de casos en los que existe lesión efectiva de un derecho fundamental pero el caso no reviste trascendencia constitucional, por lo que no merece una decisión de fondo en un amparo constitucional.

14 Auto de la Sala Especial del art. 61 LOPJ 13803/2018, de 28 de noviembre, ponente, Jorge Rodríguez-Zapata (ECLI:ES:TS:2018:13803A).

15 Rodríguez-Zapata (2019: 305 y 388). 
Esta opinión ha sido refrendada por los Autos de la Sección de admisión de la Sala Tercera del Tribunal Supremo de 1 de marzo de 2017 (Recurso de casación 88/2016) ${ }^{16}$ y de 22 de marzo de 2017 (Recurso de casación $49 / 2017)^{17}$ que se ven obligados a reconocer

las dificultades que plantea la apreciación de un interés casacional objetivo para la formación de la jurisprudencia cuando se denuncia la vulneración del derecho a obtener la tutela judicial efectiva, con infracción del art. 24 CE y de aquellos otros preceptos que exigen a las sentencias y demás resoluciones judiciales ser coherentes con las pretensiones de las partes [porque] la noción de incongruencia omisiva y los referidos preceptos han sido objeto de una abundante y reiterada jurisprudencia, tanto del Tribunal Constitucional como del Tribunal Supremo, por lo que difícilmente se harán necesarios nuevos pronunciamientos de esta Sala.

El auto citado de la Sección de Admisión de 1 de marzo de 2017 trata de arreglar la situación, movido por el plausible deseo de atender en esos supuestos al derecho del recurrente ius litigatoris, dado que no se garantiza la doble instancia en el nuevo sistema. Adopta por ello la solución de considerar que es posible subsanar uno de los tipos de incongruencia, la omisiva $-\mathrm{O} e x$ silentio - mediante una solicitud de complemento de sentencia de los arts. 267.5 LOPJ y 215.2 LEC y, en tal sentido, declara que:

[...] cuando [...] el recurrente se queje en casación de la incongruencia omisiva de la sentencia que combate, haciendo pivotar sobre tal silencio jurisdiccional su pretensión ante el Tribunal Supremo, resulta legítimo exigirle que antes acredite, como presupuesto de procedibilidad, haber instado sin éxito el complemento de la sentencia por el cauce previsto en los artículos 267.5 LOPJ y 215.2 LEC.

Por ello declara necesario "pro futuro", que, en casos de incongruencia por omisión de pronunciamiento, los recurrentes en casación intenten la subsanación de la falta acudiendo al incidente de complemento de sentencia de sentencia ${ }^{18}$.

16 ATS 1450/2017 (ponente, J. Huelin Martínez de Velasco) (ECLI:ES:TS:2017:1450a). 17 ATS 2126/2017 (ponente, Manuel V. Garzón Herrero) (ECLI:ES:TS:2017:2126A).

18 Dada la novedad y alcance del supuesto el Auto 1450/2017 declara una retroacción de actuaciones al momento en que se notificó la sentencia a la parte recurrente para que pueda instar el incidente oportuno. Aunque loable, es muy discutible desde un punto de vista dogmático la solución porque la Sección de admisión (cuyas competencias determina el art. 90 de la LJCA) no es un Tribunal Constitucional ni tiene sus poderes y suscita muchas dudas que pueda extender su jurisdicción, en una retroacción de actuaciones, a un momento anterior a la preparación del recurso para el que se le atribuye competencia o que module las competencias de la Sala «a quo», que quedan, a mi en- 
No todas las incongruencias por omisión se pueden subsanar de esta forma sin afectar a la prohibición de variar las resoluciones que pronuncien que impone a los tribunales el art. 267.1 LOPJ. Tampoco es hábil, desde luego, para remediar los demás tipos de incongruencia. Lo ha intentado, sin embargo, la Sección de Admisión de recursos de la Sala Tercera en auto de 11 de diciembre de 2017 (casación 3711/17) en el que fuerza de nuevo su interpretación, esta vez del incidente de nulidad de actuaciones del art. 241 de la LOPJ que nos ocupa, para tratar que las salas de instancia remedien los demás tipos de incongruencia, después de que el Tribunal Supremo haya inadmitido el recurso de casación interpuesto frente a ellos por carencia de interés casacional objetivo ${ }^{19}$.

En el ATC 65/2018, de 18 de junio, el Tribunal Constitucional vierte serias dudas sobre esa solución ${ }^{20}$.

\section{BALANCE Y PERSPECTIVAS DE REFORMA}

La situación expuesta muestra que es necesaria una reforma legislativa del incidente de nulidad de actuaciones.

tender, fuera de su jurisdicción. En el mismo sentido anulan actuaciones y retrotraen a dicho momento, sin embargo, el Auto de 22 de marzo de 2017 (Casación 49/2017), ya citado, e innumerables autos posteriores. La solución, aunque suscita dudas evidentes, ha sido eficaz para remediar infracciones procesales flagrantes en un contexto en el que no existe la doble instancia y en el que no sería posible recurrir al art. 241 LOPJ por existir una vía de recurso y carecer en consecuencia de firmeza la resolución a recurrir.

19 ATS 11433/2017. Ponente, Manuel V. Garzón Herrero (ECLI:ES:TS: 2017:1 1433A). El vicio imputado en el caso no era la incongruencia negativa sino una incongruencia «interna» y «extrapetita». La respuesta del Tribunal consiste en forzar la posibilidad de presentar un incidente de nulidad de actuaciones del art. 241 LOPJ ante la Sala de Instancia. Tras negarse a admitir el recurso de casación reconoce en el fallo, sin embargo, que abre la posibilidad de interponer el incidente de nulidad de actuaciones contra la resolución del Tribunal a quo desde la inadmisión del recurso de casación, pues es desde ese momento desde el que — entiende la Sala de admisión — la sentencia de instancia no es susceptible ya de recurso alguno, ordinario o extraordinario, que es la condición a la que el art. 241.1 LOPJ supedita la válida interposición del incidente de nulidad de actuaciones.

20 Al tiempo que hace la siguiente observación en su FJ 5: «Tampoco cabe olvidar que el recurso de amparo exige, tras esa reforma legal [la de la LO 6/2007] como requisito propio la especial trascendencia constitucional [art. 50.1 b) LOTC] y, en principio, no es fácil que ésta pueda concurrir si el debate no presenta previamente interés casacional». 
El incidente no debe ser sobrevalorado como la única vía alternativa a la inadmisión de un recurso de amparo derivada de la objetivación del recurso de amparo desde la reforma de la Ley Orgánica del Tribunal Constitucional del año 2007. El art. 241 LOPJ no es el desarrollo adecuado al amparo judicial ordinario que prevé el art. 53.2 de la Constitución; tampoco lo son los procedimientos especiales de protección existente a día de hoy. Por ello la situación actual no es satisfactoria.

Hay que aplaudir, sin embargo, la modificación del año 2007 por la que se amplía el incidente a "cualquier vulneración de un derecho fundamental de los referidos en el art. 53.2 de la Constitución». Parece evidente que hay que superar el estrecho marco del art. 24 de la Constitución para estos incidentes y que son las circunstancias de cada caso las que determinen el derecho fundamental sustantivo o procedimental que se invoque. Así ha ocurrido, por ejemplo, en la práctica de admisión de recursos de casación en el Tribunal Supremo en la que han prosperado varios incidentes de nulidad planteados frente a resoluciones de inadmisión de recursos de casación fundados en la invocación del principio de igualdad del art. $14 \mathrm{CE}$, su vertiente de igualdad en la aplicación jurisdiccional de la Ley ${ }^{21}$. Carecen por ello de consistencia las voces doctrinales que han pedido volver a limitar el incidente a los supuestos previstos desde el año 1997 al 2007.

La situación actual exigiría crear un auténtico amparo judicial ordinario como se había previsto, y luego se abandonó, en el programa de desarrollo constitucional del año 1979, siguiendo el precedente de los llamados tribunales de urgencia en la Constitución de 1931 de nuestra Segunda República, que nunca se llegaron a crear.

Reduciendo el incidente de nulidad a un ámbito mucho más modesto que el que exige el art. 53.2 CE puede concluirse, como balance de su introducción en 1997, que ha sido una válvula de escape muy adecuada para remediar los supuestos de vicios de procedimiento e incongruencia de la sentencia que le dieron origen.

Ceñida a esta perspectiva, su utilización ha sido satisfactoria, con el único problema de su articulación con el recurso de amparo, que ve garantizada su subsidiariedad a través del mismo con problemas de interpretación que recaen en forma abrumadora sobre la parte recurrente. La ya citada STC 182/2011

21 Cfr., por ejemplo, ATS 2338/2021, de 18 de febrero de 2021 [(ponente, Dimitry T. Berberoff Ayuda) (ECLI:ES:TS:2021:2338A)], que estima un incidente de nulidad promovido por el abogado del Estado (que invocó el art. $14 \mathrm{CE}$ ) y admite a trámite un recurso de casación por haber admitido antes a trámite la misma sección un recurso idéntico. 
puso de relieve, de manera elocuente, esas dificultades. El recurrente puede encontrarse, dijo, "ante una encrucijada difícil de resolver, toda vez que si no utiliza todos los recursos disponibles dentro de la vía judicial ordinaria su recurso de amparo podrá ser inadmitido por falta de agotamiento de la vía judicial previa, y si decide, en cambio, apurar la vía judicial, interponiendo todos los recursos posibles o imaginables, corre el riesgo de incurrir en extemporaneidad al formular alguno que no fuera en rigor procedente». Corresponde a la jurisprudencia constitucional y ordinaria resolver adecuadamente estas situaciones en los casos dudosos, sin olvidar que, en último extremo, existe la garantía del Tribunal Europeo de Derechos Humanos.

El Tribunal Constitucional podría, si considerase sus normas reguladoras con la flexibilidad exigible a los supuestos graves que se examinan, determinar que en los casos en los que ha habido lesión de un derecho fundamental y esta no ha logrado ser remediada por la vía especial de protección de los derechos fundamentales ni por el incidente de nulidad del art. 241 LOPJ, podría admitir a trámite el amparo y delegarlo en forma inmediata a una de sus secciones, que son hoy órganos externos de enjuiciamiento. Bastaría una sentencia muy breve y de simple aplicación de doctrina ya emitida por una de sus secciones para mitigar la desprotección masiva de derechos fundamentales que se ha producido desde la reforma del año 2007 y que persiste a día de hoy por la evolución que he expuesto. La carga de trabajo de esa interpretación novedosa sería perfectamente asumible en cuanto los letrados del Tribunal Constitucional controlan a la perfección si ha existido o no la lesión de un derecho fundamental en la fase de admisión. Los notables esfuerzos de interpretación de la Sala Tercera del Tribunal Supremo con los imaginativos complementos de sentencia y los incidentes de nulidad en los casos de error judicial y para reparar los despropósitos generados por la reforma del recurso de casación en lo contencioso-administrativo son un buen ejemplo que, tal vez, podría haber intentado una jurisprudencia constitucional que en los últimos años se ha mostrado más rígida en la interpretación que la jurisdicción contencioso-administrativa ${ }^{22}$.

El incidente de nulidad de actuaciones es un remedio excepcional configurado en forma correcta por la legalidad procesal ordinaria, que es la que lo ha definido, aunque en su regulación actual provenga de la reforma de la LOTC y resulte vinculado en forma estrecha al recurso de amparo constitucional.

De lege ferenda hay que insistir en la conveniencia de que el incidente sea resuelto por un órgano jurisdiccional con una composición distinta de aquel

22 Rodríguez-Zapata (2013: 251). 
al que se imputa la infracción constitucional. El legislador debería proveer los medios para crear secciones especializadas en los órganos colegiados o recursos devolutivos en los unipersonales. Al menos así debería ser en los supuestos - escasos en la práctica procesal- en los que no proceda la inadmisión del incidente por una simple providencia motivada por no plantearse propiamente más que un intento último de que se considere lo ya resuelto en sentencia. Estas providencias sí pueden ser encomendadas al mismo órgano jurisdiccional que dictó la resolución impugnada. No hay riesgo de abuso porque existe la garantía de que una insuficiencia en la motivación de esas providencias o un exceso en la inadmisión va a ser controlada de seguido por el Tribunal Constitucional en los casos en los que no se cumpla el canon de arbitrariedad, irrazonabilidad o error patente fijado por el propio Tribunal Constitucional para el control de estas resoluciones.

En los casos de admisión a trámite de los incidentes, una reforma del art. 241 LOPJ debería encomendar la resolución a un órgano distinto o con una composición diferente del que dictó la resolución controlada. La creación de secciones especializadas en la protección de derechos fundamentales, en los tribunales en los que sea posible o la remisión a órganos distintos de los incidentes podría ser prevista sin dificultad por el legislador.

El riesgo de obligar a retractarse al órgano que ha dictado la resolución, que ha señalado la jurisprudencia a que hemos pasado revista, desaparecería de esta forma. Debería exigirse al promotor de estos incidentes una justificación formal y circunstanciada de los extremos en los que se considera que la resolución impugnada se aparta en su ponderación de derechos fundamentales o en la extensión que se da a un derecho concreto de la jurisprudencia constitucional o del TEDH. En tales casos sería posible y útil crear auténticas cuestiones de amparo $^{23}$, formuladas sobre la base de nuestra dilatada experiencia en las cuestiones de inconstitucionalidad del art. 35 y siguientes de la LOTC o de las cuestiones de ilegalidad de los arts. 123 y siguientes de la LJCA. El órgano jurisdiccional, inmediatamente antes de resolver el incidente, podría plantear una cuestión de amparo al Tribunal Constitucional para que este resolviese en forma semejante a como se pronuncia en las cuestiones de inconstitucionalidad, ratificando o modulando su doctrina constitucional sobre la cuestión que se le plantea. El órgano jurisdiccional proponente de la cuestión de amparo debería arbitrar las medidas cautelares necesarias mientras se resuelve la cuestión planteada y la doctrina del Tribunal Constitucional vincularía, como es lógico, la resolución del órgano jurisdiccional ordinario. La colaboración institucional entre el Tribunal Constitucional y el Tribunal Supremo se

23 Rodríguez-Zapata (2013: 253). 
alejaría de las fricciones que han marcado muchas veces las relaciones entre ambos órganos.

En cualquier caso, de lege ferenda el incidente de nulidad debe ser modulado y ampliado; en ningún caso debe ser suprimido como, con cierto apresuramiento, ha propuesto un sector de la doctrina. Con dicho incidente está en juego el equilibrio en nuestro sistema de protección de los derechos fundamentales, que es uno de los bienes más preciosos del sistema democrático de la Constitución de 1978.

\section{Bibliografía}

Guasp, J. (1950). Comentarios a la Ley de Enjuiciamiento Civil. Madrid: Aguilar.

Rodríguez-Zapata, J. (2013). Jurisprudencia constitucional y jurisprudencia administrativa. En Baena del Alcázar (coord.). La Reforma del Estado y de la Administración Pública. Madrid: Instituto Nacional de Administración Pública.

- (2018). Teoría y Práctica del Derecho Constitucional. Madrid: Tecnos.

- (2019). Fundamentos de lo Contencioso-Administrativo. Madrid: Tecnos.

Serra, M. (1985). Comentarios a la reforma de la Ley de Enjuiciamiento civil (Ley 34/1984 de 6 de agosto de 1984). Madrid: Tecnos. 